\title{
Usefulness, Accessibility and Safety of using a Bag for Ovarian Cystectomy
}

\author{
Ahmed Hassan* \\ Obstetrics and Gynecology, Helwan University, Egypt \\ *Corresponding author: Ahmed Hassan, Obstetrics \\ and Gynecology, Helwan University, Egypt
}

Received: February 14, 2019; Accepted: February 15, 2019; Published: February 26, 2019

\begin{abstract}
This is a prospective study, which was made to evaluate the usefulness of laparoscopic cystectomy of unopened ovarian cyst using a waterproof laparoscopic bag.

Aim: The aim is to hinder intraperitoneal leakage from rupture of a cyst 170 patients participated in this study. In 3 women, the cyst were on both ovaries The laparoscopic sac did not rupture in any women.

Results: Mean diameter of the cysts was 5.1, 5.8, 5.3, 6, 4.8 and $5.5 \mathrm{~cm}$ in mucinous cystadenoma, serous cystadenofibroma, serous cystadenoma, simple serous cyst, benign teratoma and borderline tumors respectively.

In 102 out of $121(84.29 \%)$ cases, cystectomy was finished without rupture, whereas in 19 women out of 121 (15.7\%) women the cyst ruptured. Spillage occurred only in three cases, 2 cases of benign dermoid and one case of serous cystadenoma. Some ovarian cysts ruptured but in the presence of the endoscopic bag, there was no spill of any content in cysts less than $6 \mathrm{~cm}$. But a slight leakage happened although there was great effort to prevent this spill in $3 / 119(2.47 \%)$ women with cysts more than $6 \mathrm{~cm}$ of 2 dermoid and one serous cyst.

Conclusion: Proper decision in managing ovarian cysts in very important as when we combine the following factors; the type of the cystic lesion based on ultrasonographic picture with excluding malignant possibility and a mean cyst diameter of less than $6 \mathrm{~cm}$ with the use of endoscopic bag gives the best chance for proper excision of ovarian cysts laparoscopically with less possibility for cyst rupture and spillage and even if rupture occurs leakage of cyst contents could be prevented by the endoscopic bag. While larger cysts more than $6 \mathrm{~cm}$ or malignant cystic lesions needs more care and are more hard to deal and needs more future researches.
\end{abstract}

\section{Introduction}

Introduction of new technologies in endoscopic surgeries are increasing in the past few years. These techniques allows complete excision of benign ovarian cysts to be easy safe technique [1].

Endoscopic interventions needs lower duration of hospital stay with less recovery period $[1,2]$.

Excision of an ovarian cyst within a bag is a technology that could be used in adnexal cysts $[3,4]$.

The usefulness of this bag is in to hinder leakage of contents in case of intra operative opening of the cyst but this was not properly evaluated in a prospective way $[5,6]$.

\section{Materials and Methods}

Patients with ovarian cysts coming to suez canal university hospitals and helwan university hospitals and Algezeera hospital, Egypt complaing from lower abdominal pain and proved to have ovarian cysts less than $6 \mathrm{~cm}$ were recruited to participate in this study that was conducted in the period from June 2016 till September 2018. The study was approved by local ethical committee. 121 women participated in this study.
The study was made to address usefulness of a large laparoscopic bag in avoiding leakage of contents after rupture of laparoscopically excised cysts. We also attempted to determine the possibilities of rupture for each of the several histologically different ovarian cysts that are present in young women included in the research in whom an attempt to remove the cyst intact was tried. Also the aim was to know the preoperative and intraoperative risk factors for rupture, and leakage after rupture, and know the limitations for trying excision of an intact cyst versus doing a puncture and evacuation of its contents inside the bag.

Inclusion criteria included women in the age between $20-45$ yearold aiming to preserve the ovary, women with ovarian cystic lesions, which have a suspicion of malignancy or has endometriomas were excluded from the study.

The following preoperative investigations in the form of tumor markers (CA 125 - CA19-9 - CEA, Alpha -fetoprotein, and $\beta$-hCG), transvaginal ultrasound full laboratory investigations, CT abdomen and pelvis were made.

Transvaginal Ultrasonography assess the ovarian cyst for either unilateral or bilateral its content, presence of a solid component, size, presence of septations, papillary projections the thickness of the its 
Table 1: Shows a descriptive data of the study.

\begin{tabular}{|l|c|c|c|c|}
\hline & Mean \pm SD & Median & Minimum & Maximum \\
\hline Age (years) & $41.32 \pm 5.84$ & 31 & 22 & 46 \\
\hline Body weight (Kg) & $87 \pm 12.73$ & 81 & 68 & 109 \\
\hline Height (M) & $164.33 \pm 5.37$ & 163 & 155 & 173 \\
\hline BMI & $32.23 \pm 6.27$ & 28 & 21 & 41 \\
\hline
\end{tabular}

wall, intra cystic vascularity

Laparoscopic surgery was made using 4 trocars: one primary trocar was introduced through a vertical intraumbilical incision, allowing the use of a $10 \mathrm{~mm}, 0$ - degree laparoscope. And 2 accessory trocars $(5 \mathrm{~mm})$ were inserted in the lower abdomen lateral to the inferior.

After insertion of the laparoscope, a careful evaluation of the pelvis and abdomen was made and peritoneal washings or free peritoneal fluid was taken for cytological examination. The waterproof endoscopic bag (Unimax, Medical Technology Promedt, Consulting $\mathrm{GmBH}, 5$ "X 7") was introduced into the peritoneal cavity wrapped tightly into its plastic applicator through the umbilical trocar and opened by unrolling it with a forceps, after replacing the laparoscope. The lesion-harboring adnexa was placed and kept inside the bag throughout its dissection.

The cyst was deflated inside the endoscopic bag by the use of a needle and a suction pump to decrease its volume and make the extraction of the bag and the remaining cyst feasible without spillage in abdominal wall.

\section{Results}

In the present study, there was no statistical significance regarding demographic data of the women included in the study.

\section{Discussion}

In a previous study was made on young women who need to preserve their future fertility. They thought that preventing leakage during excision of a cyst is of high value not only for malignant lesions but also for benign lesions, due to the that the spilled fluid may cause peritonitis and cause adnexal and intraperitoneal adhesions, even in the absence of symptoms $[7,8]$.

The operative management of ovarian cysts represents one of the famous indications for laparoscopic surgery.

Such a preoperative diagnosis may include several pathological nonneoplastic and neoplastic lesions. Accurate preoperative and intraoperative diagnosis might be accessible on some situations and infeasible in others, for the reason that different pathologies may have similar ec hopattern [9-11].

In the present research, the mean diameter of the cysts was $5.1,5.8,5.3,6,4.8$ and $5.5 \mathrm{~cm}$ in mucinous cytstadenoma, serous cystadenofibroma, serous cystadenoma, simple serous cyst, benign teratoma and borderline tumors respectively.

The main factor that must be put into consideration when deciding the proper way to excise a cyst is its maximal diameter.

Rupture of a cyst does not definitely result in leakage of its contents into the peritoneal cavity, providing that it is always being excised in an endoscopic sac.

A previous study made Stelios Detorakis showed that the relative risk for rupture increases by $48 \%$ for every $1 \mathrm{~cm}$ increase in cyst diameter, while the relative risk for leakage increases by four folds respectively. From a clinical importance, the most important issue is not to prevent rupture of a cyst but to prevent its leakage [12].

Moreover in the current study, In 102 out of 121 (84.29\%) cases, cystectomy was finished without rupture, whereas in 19 women out of $121(15.7 \%)$ women the cyst ruptured. Spillage occurred only in three cases, 2 cases of benign dermoid and one case of serous cystadenoma.

Also in contrary to the present study, the cutoff point in cyst diameter with a major clinical importance was recognized at $8 \mathrm{~cm}$ in a study made by Stelios Detorakis et al. revealing that $43.8 \%$ of the cysts with mean cyst diametr $\geq 8 \mathrm{~cm}$

sustained leakage of their contents, compared with only $1.1 \%$ of those $<8 \mathrm{~cm}$, they also thought that the metod of excision of an intact cyst is effective and oncologically safe for lesions equal or less than 8 $\mathrm{cm}$.

In a previous study made by Stelios Detorakis et al. showed that the low rate of rupture for those cystic lesions that were described as suspicious. Overall, only $3 / 14(21.4 \%)$ cysts in this group (4 borderlines, 5 cystadenofibromas, 2 serous cystadenomas, and 3 teratomas) ruptured, with $0 \%$ leakage.

They used the modified technique with laparoscopic bag, even in the group of women with borderline ovarian lesions, the rupture rate was $50 \%$ (one in a pregnant woman) with zero \% leakage [12].

Also in the present study, Some ovarian cysts ruptured but in the presence of the endoscopic bag there was no spill of any content in cysts less than $6 \mathrm{~cm}$.

But a slight leakage happened in $3 / 119$ (2.47\%) women with cysts more than $6 \mathrm{~cm}$ of 2 dermoid and one serous cyst in these cases the

Table 2: Showing classification of cases according to pathological results of excised cysts.

\begin{tabular}{|c|c|c|c|c|c|c|}
\hline Histopathology & Mean Cyst diameter (Mean) & Rupture Yes & No & Leakage Yes & No & Total \\
\hline Mucinous cystadenoma & 5.1 & 1 & 23 & 0 & 24 & 24 \\
\hline Serous cystadenofibroma & 5.8 & 2 & 9 & 0 & 11 & 11 \\
\hline Serous cystadenoma & 5.3 & 7 & 18 & 1 & 24 & 25 \\
\hline Simple serous cyst & 6 & 2 & 27 & 0 & 29 & 29 \\
\hline Benign teratoma & 4.8 & 6 & 22 & 2 & 26 & 28 \\
\hline Borderline ovarian tumor & 5.5 & 1 & 3 & 0 & 4 & 4 \\
\hline
\end{tabular}


mean cyst diameter of these cysts was more than $6 . \mathrm{cm}$

In accordance with our study, the study made by Stelios Detorakis revealed that laparoscopic ovarian cystectomy might be made safely in a BOT without leakage and that oophorectomy mustnot be the obligatory method of choice for suspicious cystic masses management.

\section{Conclusion}

Proper decision in managing ovarian cysts in very important as when we combine the following factors; the type of the cystic lesion based on ultrasonographic picture with excluding malignant possibility and a mean cyst diameter of less than $6 \mathrm{~cm}$ with the use of endoscopic bag gives the best chance for proper excision of ovarian cysts laparoscopically with less possibility for cyst rupture and spillage and even if rupture occurs leakage of cyst contents could be prevented by the endoscopic bag.

\section{References}

1. Mettler L, Semm K, Shive L. "Endoscopic management of adnexal masses," Journal of the Society of Laparoendoscopic Surgeons. 1997; 1: 103-112.

2. Canes M, Rabischong B, Houlle C, Revaz B, Kris J, Antoine S, et al. "Laparoscopic management of adnexal masses: a gold standard?" Current Opinion in Obstetrics and Gynecology. 2002; 14: 423-428.

3. Shushan A, Protopapas, Magos AL. "Laparoscopic "oophorectomy-in-a bag"an alternative to laparotomy for the evaluation of suspicious ovarian masses," Journal of Obstetrics and Gynaecology. 2001; 21: 399-401.

4. Zanatta MMS, Rosin, Gibran L. "Laparoscopy as the most effective tool for management of postmenopausal complex adnexal masses when expectancy is not advisable," Journal of Minimally Invasive Gynecology. 2012; 19: 554561.
5. Slangen T, Beretta P, Catalano G, Marana R, van Herendael B. "Bag surgery as part of a protocol to treat ovarian masses by laparoscopy," The Journal of the American Association of Gynecologic Laparoscopists. 1994; 1.

6. Yuen PM, Rogers MS. "Laparoscopic removal of ovarian cysts using a zipper storage bag," Acta Obstetricia et Gynecologica Scandinavica. 1994; 73: 829831.

7. Milingos S, Protopapas A, Drakakis P, Liapi A, Loutradis D, Rodolakis A, et al. "Laparoscopic treatment of ovarian dermoid cysts: eleven years' experience," Journal of the American Association of Gynecologic Laparoscopists. 2004; 11: 478-485.

8. Kondo W, Bourdel N, Cotte B, Tran X, Botchorishvili R, Jardon K, et al. "Does prevention of intraperitoneal spillage when removing a dermoid cyst prevent granulomatous peritonitis?" BJOG-An International Journal of Obstetrics and Gynaecology. 2010; 117: 1027-1030.

9. Takemoto S, Ushijima K, Kawano R, Fukui A, Terada A, Fujimoto T, et al. "Validity of intraoperative diagnosis at laparoscopic surgery for ovarian tumors," Journal of Minimally Invasive Gynecology. 2014; 21: 576-579.

10. Covens L, Dodge JE, Hachette C, Elite LM, Le T, Devries-Abound M, FungKee-Fung M, et al. "Surgical management of a suspicious adnexal mass: a systematic review," Gynecol Oncol. 2012; 126: 149-156.

11. Canes M, Meshach R, Wattles A, Botchorishvili R, Rabischong B, Jardon $\mathrm{K}$, et al. "Frozen section in laparoscopic management of macroscopically suspicious ovarian masses," Journal of the American Association of Gynecologic Laparoscopists. 2004; 11: 365-369.

12. Detorakis S, Vlachos D, Athanasiou S, Grigoriadis T, Domali A, Chatzipapas I, Stamatakis E, et al. Minimally Invasive Surgery. 2016; 2016.
Austin J Obstet Gynecol - Volume 6 Issue 1 - 2019

Submit your Manuscript | www.austinpublishinggroup.com

Hassan. (C) All rights are reserved
Citation: Hassan A. Usefulness, Accessibility and Safety of using a Bag for Ovarian Cystectomy. Austin J Obstet Gynecol. 2019; 6(1): 1133 